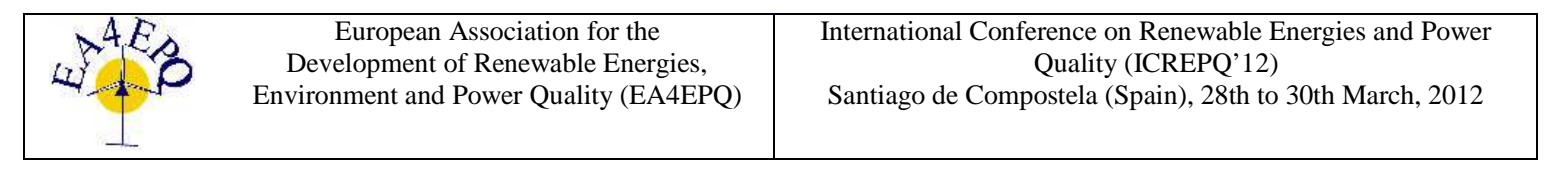

\title{
Ecoaldeas or Self-Sustainable Communities and renewable energy solutions (SSC)._First approach Ecuador and Mexico
}

\author{
A.López Agüera ${ }^{1,2}$, J. Domingues Azevedo ${ }^{1,5}$ I. Rodríguez Cabo ${ }^{1,2}$, D. Rey Rey ${ }^{1,2}$, \\ V. Gándara Villadoniga ${ }^{1}$, E. Vieites Montes ${ }^{1,2}$, J Peralta ${ }^{1,3}$,$$
\text { I. Sosa }^{1,4}, \text { J. Guerra }^{5} \text {, M. Alguacil }{ }^{6}
$$ \\ Department of Particle Physics \& Galician Institute of High Energy Physics. \\ ${ }^{1}$ Sustentable Energetic Applications Group. ${ }^{2}$ Astroparticle Group. \\ Physics Faculty, Santiago of Compostela University \\ Rúa Xosé María Suárez Núñez. s/n 15782. Santiago of Compostela (Spain) \\ Phone/Fax number: 0034981563100 ext.. 14000, e-mail: a.lopez.aguera@usc.es, joao.domingues@usc.es \\ ${ }^{3}$ Escuela Superior Politecnica del Litoral Centro de Desarrollo Tecnologico SustentableVia Perimetral 30.5 Km, \\ Guayaquil Ecuador Phone/Fax number: 00530042269359 cdts@espol.edu.ec \\ ${ }^{4}$ Instituto Tecnológico de Sonora. 5 de Febrero 818 Sur, Col. Centro, Ciudad Obregón, Sonora, México. \\ ${ }^{5}$ Escuela de Arquitectura, Universidad Católica del Norte Antofagasta, Chile \\ ${ }^{6}$ Universidad Nacional de Cuyo. Instituto de la Energía. Centro Universitario .M5502JMA. Mendoza, Argentina
}

\begin{abstract}
A multidisciplinary project focused on the development of self-sustainable communities (ecoaldeas) is presented. The final objective is to implement a protocol of actions able to prove that common integral solutions based on renewable energies and sustainable development can fulfil the community's requirements. Moreover, it will be reproducible in other communities in different geographical, social and economic conditions, making them as self-sustainable as possible improving their quality of life. Initial hypothesis, dominant communities parameters, protocol development, technical solutions and first experiences are presented.
\end{abstract}

\section{Key words}

"Ecoaldea", Sustainable communities, Renewals, Residues, Water

\section{Introduction}

Historically, the main strength and "equivalent resilience" of small communities (independent of their geographical location) was the wisdom of use their own resources with the highest efficiency. They were dependent almost exclusively on their own management of food, water, energy, residues, building materials, medicines and community relations.

Their solutions provide them year round supply for basic needs and the products surplus they had were used as an economical remainder by selling or just exchanging them.

The globalization of the last decades, the cheap energy associated, the global transportation system and the abandonment of small communities from the youngest people had generated that those communities get almost fully dependent on external supply networks, and correspondent abandonment and lost of their ancestral knowledge and natural resilience.

In the present concept of our project we define ECOALDEA or self-sustainable community as an intentional community with a common objective: to be socially, ecologically and economically sustainable. Their development will be based on the respect for the environment, the use of renewable energies and sustainability.

Since 1974, when R. Gilmar [1] first presented the concept of ecoaldea (green villages), a huge 
number of more or less individual initiatives have been developed worldwide, with different degree of results. No general conclusions could had been obtained and their possible reproducibility is more than doubtful.

The following document describes the protocols of actuation, the activities developed and the first results obtained at the moment.

\section{Objectives and concepts}

A multidisciplinary team of experts from Iberoamerican Universities in 2009 began a new initiative with a clear objective: to demonstrate the viability of a new model for sustainable development in which a community can be selfsufficient independently of their idiosyncrasy (geography, economy, social development and so on). Self-sustainability needs to be understood in a global sense, integrating energy resources exploitation, self-food production, water management, urban planning, and efficient architecture, as well as social, educational and economical development based on regional productivity activities.

All actions proposed are planned to promote an extra social and economic development to the communities.

One of the lacks found in early projects was the evaluation of the impacts. Mainly, evaluations were made concerning the economical impact of renewable energetic solutions.

In SSC the assessment of impacts in the communities is focused in several criterions as social, environmental, economical and energetic context of the communities.

SSC consider the evaluation of impacts in a 3-5 year time. SSC project develop a mathematic quantification method based on personal surveys. This method allows quantifying the satisfaction of the communities, planning the future viability of this kind of projects in different communities as find problems and proposing solutions according to the opinion of the main clients, the communities.

The results obtained from surveys are:

- Quantitative

- Qualitative

- Opinion

Quantitative results allow evaluators to obtain statistics from the 5 year project concerning material and quantifiable consumables.

Qualitative results quantify mathematically the "satisfaction"/ "dissatisfaction" of communities with the progress of the project and utilization of the renewable energy based solutions.
Opinion results are one of the key points of the project allowing us to readapt the solutions according to the real needs of each community.

\section{Working protocols}

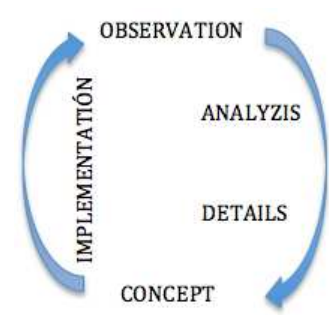

Figure 1. Cycling methodology used in the project.

The project is performed as an horizontal and cooperative structure, in a way that the priorities of every partner will be included in the project with the agreement of all partners. Once the community target is identified, we define the main tasks to perform as:

A. Observation and delimitation of scenarios of action in the environment of each group.

1) Population

2) Rural-urban context

3) Weather condition

4) Economic and social characteristics

5) Assessment of needs and resources

6) Local characteristics

B. Analysis and evaluation of energy resources, water availability, land fertility, residues etc.

C. Identification of the agents participating in the process and project details focusing.

1) Wealth-generating agents

2) Technological agents

3) Governmental agents

4) Economic agents

5) Social agents

\section{C1. Study of Energy Markets}

1) Planning, policy analysis and scenarios

2) Market Analysis

3) Energy regulations

4) Energy as a source of development and competitiveness of the regions

D. Proposal of project design concepts based on self-managed energy solutions. 
E. Definition of the logistic chain and priority actions selection.

F. Adaptation and implementation of technologies to each scenario

1) Description of the process to develop

2) Implementation of the selected process

3) Awareness and social education.

G. Observation and evaluation of the Initiative as a source of development

1) Social return

2) Economic return

3) Environmental Benefit

4) Reproducibility of the Initiative

5) Resilience level

\section{Developed activities}

The community target must be selected carefully. The main constraint has been the priority of diversification. Different zones of geographic influence, different energetic and water resources, social, industrial and economical environment have been selected to cover a wide range of possible scenes of action. This will facilitate future reproducibility. Nevertheless, the selection of a non-biased sample of communities is not simple. The project visualizes a radical change in the energetic management model, which is difficult to implant in zones with energetically efficient and sophisticated systems. This forced us to select communities without electrification and residues management, with high external dependence on food resources, water supply and/or fossil fuels.

Rural, semi urban and urban communities have been chosen, as well as indigenous communities with traditional life. Communities of different economies (agriculture, ranching, fishing, tourism, and on the poverty line), different geographical characteristic (mountain, coast, islands) and climates.

At the present moment, we are developing interventions in communities from Chile, Ecuador, Mexico, Colombia ,Bolivia[2], Argentina and Spain [3].

\section{Ecuador (Cerrito de los Morreños)}

Population: Acording to "Direccion Provincial de Salud del Guayas" in June 2010 the population of "Cerrito de los Morreños" was aprox 720 inhabitants, where $50 \%$ of the families are at least of 5 members.

The main economic activity is fishing and mangrove swamp product recollection, wich products are sold in regional markets.

The main necessities detected in the region are: electricity, drinking water, a reliable transportation system to mainland, healthcare in the islands, residual management plan, and sustainable agriculture.

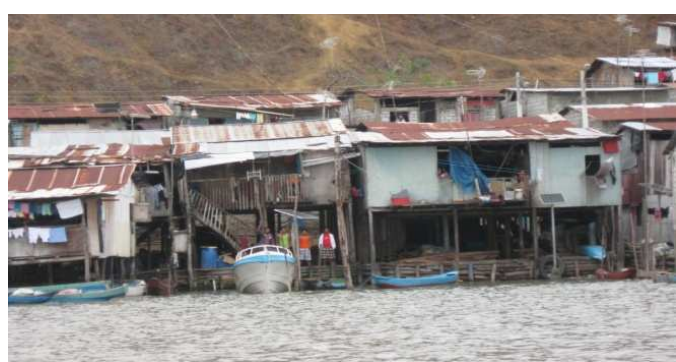

Figure 2. Cerrito de los Morreños comunity

Resources

Solar Irradiation: There are no weather stations that measures solar radiation in the Guayaquil Gulf, in this case, the solar radiation studies where done using satelital images given by the Surface meteorology and Solar Energy of NASA. [5]

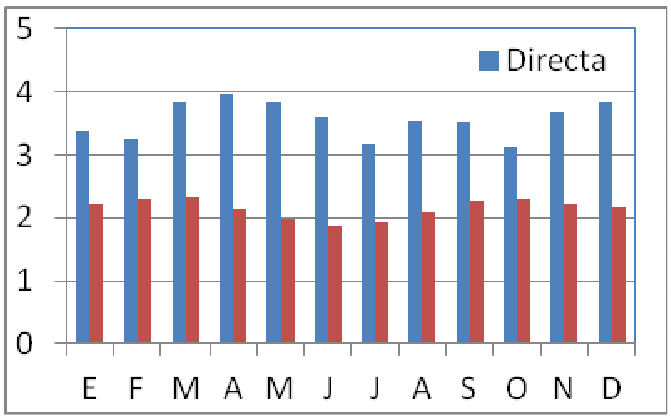

Figure 3. Average solar day by month for Guayaquil Gulf.[6]

Wind; The highest values of wind speed are presented between the months of August and December around $3.6 \mathrm{~m} / \mathrm{s}$ approximately. The predominant wind direction is South - West.

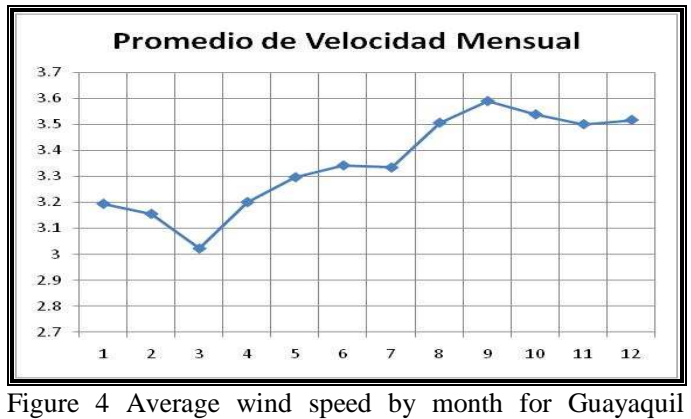
Gulf.[6] 
Precipitation: According to INOCAR in average the annual precipitation for this region is $680 \mathrm{~L} / \mathrm{m} 2$.

Developed activities

There were several interventions in the region by ONGs and by the public sector in order to cover the energy demand.

In the year of 2005, the Electricity and Renewable Energy Department installed 3 solar PV's at the elementary school of the main island; later in 2009 this system was repurposed by Eurosolar Association in order to supply energy for a computer center intended for the community. In 2010, it was installed a diesel power generator of $145 \mathrm{kWh}$ of capacity, that is currently out of service. At the end of the same year the government, through the Ecuatorian Urban Electrification for Pour Areas Fund (Fondo de Electrificacion Urbano Marginal del Ecuador), installed PV systems for 99 houses of the island. The ONGs help has been an important role for the development of the islands mainly in the social, health and education aspects.

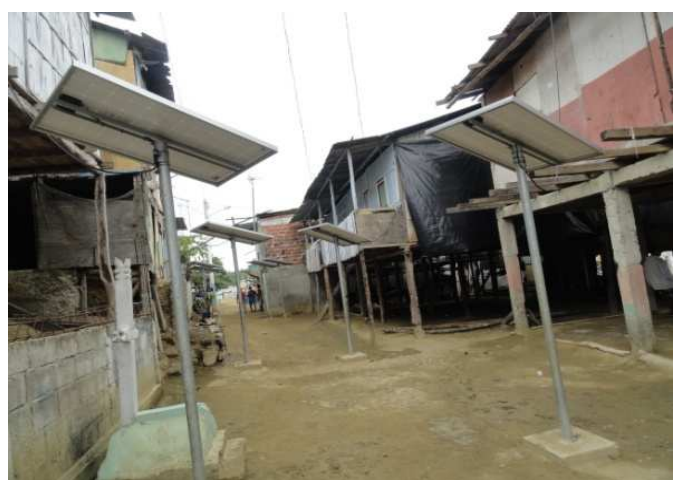

Figure 5: PV solar system installation at Cerritos de los Morreños comunity

At the present time, the activities of the group are focused in evaluation and research of the residual water, algal biomass characterization, house and public buildings energy audits, dissatisfaction and comfort level analysis, sustainable agriculture strategies and redesign of PV systems.

\section{Mexico(South Sonora Region)}

Agriculture is the most important economic activity in the region, mostly with the production of grains. [10] However, such intensive agriculture in such an arid area has had a significant negative impact of water supplies. [11]
The state has a traditional livestock industry with a reputation of quality. In the south region, beef and pork cattle are the most important.

Through the coastal line, fishing and aquaculture is really important for the region. This is one of the leading fish producing regions in the country. [10] Much of the commercial and sports fishing is essentially unregulated and has had a very pronounced impact on the Gulf of California, with commercially important species such as shrimp, have been harvested well above sustainability.

At the pre-mountain zone mining it's an important activity which has being exploited over the years. And there are some abandoned mines trough the region.

Population

According to SEDESOL two municipalities of the south of Sonora are categorized as with high marginalization and four of them are considered marginalized. The population density is 14 inhabitants per square meter; it contains $38 \%$ of the inhabitants of the state.

\section{Resources}

South Sonora region has a network of 28 meteorological stations disperse around its territory since 1997.

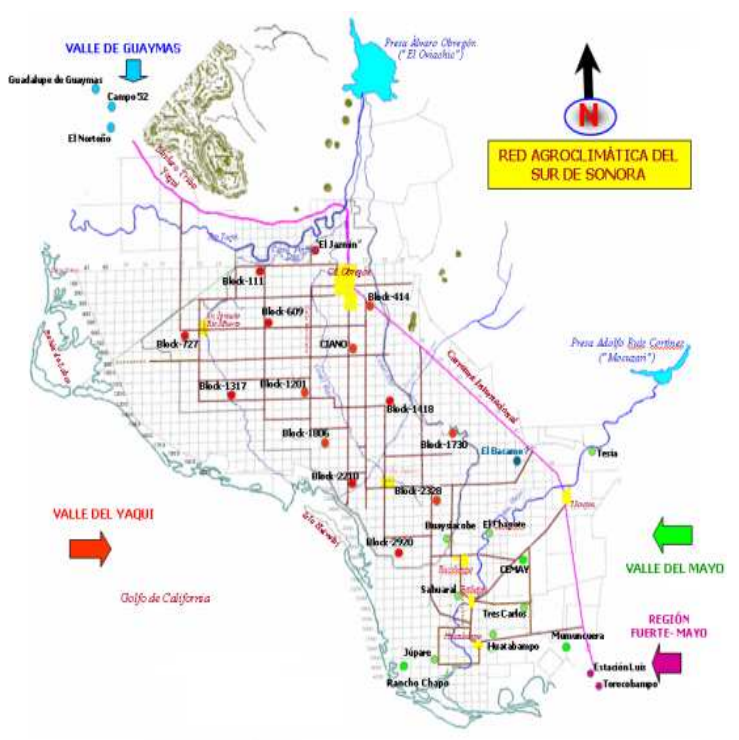

Figure 6: South Sonora Meteorological Station Network [12] 


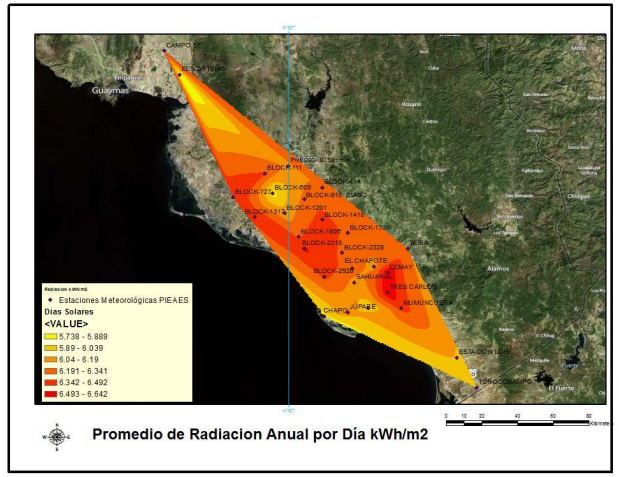

Figure 7 Annual average solar energy ( $\mathrm{MJ} / \mathrm{m} 2$ by day) at south Sonora region.

This meteorological network will help to identify potentialities within the region. Some of the results given are the high solar radiation maps as you can see in the Figure 7.

Moreover, livestock residues are already used in the largest pig farms in the region to produce biogas. However, small pig farms need to be alerted about the emissions avoided trough this method.

The south of Sonora has a rainfall of $363 \mathrm{~mm}$ per year.

\section{Conclusions}

Since the beginning of the SSC project, the numbers of involved local governments have been increasing substantially. The use of renewable energy solutions for small communities has been accepted as a reliable alternative to traditional energy generation, water management and residues utilization. Some solutions had already been implemented with positive feedback.

The main constraint we have been facing is financing renewable energy equipment's for larger scale projects. The creation of agreements with national energy agencies and departments had been one of our major focuses during all process.

The main objective for the following period is to achieve that all the involved communities could depend as less as possible from external supply sources of energy, food and water.

The two examples presented in the current article showed different characteristics that could be used in order to extrapolate the results between them and other communities. It's necessary further analysis and research since both examples are in early stages of the project.

\section{References}

2 - Solar mixed thermal and photovoltaic installation for an infantile educational-sanitary lodging in Senkata-El Alto (BOLIVIA). A. Daniel Rey Reyb, B. Manuel Alejandro Míguez Ruanovab, C. Francisco Manuel León Mayob, Iago Fernandez Oteroa, Vicente Gándara Villadónigaa, A. López Agüeraa aDepartment of Particle Physics \& Galician Institute of High Energy Physics bMaster in Renewable Energies. ICREPQ 2009

3 - Architectural Integration of Renewable Energies in Historical Cities A. López Agüeraa, I. Rodríguez Cabo a, I. Fernándeza and V. Gándaraa a Department of Particle Physics \& Galician Institute of High Energy Physics ICREPQ 2008.

8 - Preliminary method for surveying the state of batteries ageing in isolated PV systems Á. López Agüera1, E.Lorenzo2, Rute Cortizo1, Iago Rodriguez-Cabo2. 1. Departament of Particle Physics \& Institute of High Energy Physics. Astroparticle Group. Santiago de Compostela University. Spain 2. Institute of Solar Energy. Politechnic University of Madrid. Spain ICREPQ 2007

5. NASA. Surface meteorology and Solar Energy. [En linea] http://eosweb.larc.nasa.gov/sse/.

6 Instituto Oceanográfico de la Armada del Ecuador. (n.d.). INOCAR. Retrieved from INOCAR: http://www.inocar.mil.ec

7 CHIRIBOGA, P. J. (n.d.). EVALUACIÓN DE LAS ENERGÍAS RENOVABLES NO CONVENCIONALES FACTIBLES DE DESARROLLARSE EN EL ECUADOR. Quito: EPN.

8. TECH4CDM. (2009). La Electrificación Rural en el Ecuador. Quito.

10 - "Actividad Económica". Enciclopedia de Los Municipios y Delegaciones de México Estado de Sonora. Mexico: Instituto para el Federalismo y el Desarrollo Municipal. 2010. [En línea] http://www.elocal.gob.mx/wb2/ELOCAL/EMM_sonora

11- Yetman, David; Van Devender, Thomas R.. Mayo (2002). Ethnobotany : Land, History, and Traditional Knowledge in Northwest Mexico. Ewing, NJ, USA: University of California Press.

12- PIEAES. Sistema de Información Agroclimática. [En línea] 24 de febrero de 2011. [Citado el: 24 de febrero de 2011.] http://pieaes.dyndns.org/. 